\title{
The Incidence of Intestinal Obstructive Diseases in Selected Veterinary Clinics and Hospitals in South Western Nigeria
}

\author{
${ }^{* 1}$ EYAREFE O.D., ${ }^{2}$ ALONGE T.O, ${ }^{1}$ FAYEMI E.O,
}

${ }^{1}$ Departments of Veterinary Surgery and Reproduction, ${ }^{2}$ Department of Surgery, College of Medicine, University of Ibadan, Ibadan, Nigeria Correspondence:tolamega@yahoo.com, Tel.2348057921708

\section{SUMMARY}

Intestinal obstructive diseases are medical and surgical emergencies which require precise diagnosis and rapid surgical intervention. They are characterized by severe hypovolemia and septic shock secondary to devitalization of the intestinal wall. The consequent surgical complications such as ileus, adhesions and short bowel syndrome with resultant death of the patients also pose management challenges to the clinician.

This study investigated the incidence of intestinal obstructive diseases in some animals presented at selected Veterinary Hospitals and Clinics in southwestern Nigeria between 1998 and 2008. Records of surgical cases were grouped into 11 categories and further grouping of intestinal obstructive conditions in small and large animals were presented using descriptive statistics.

Intestinal obstructive conditions ranked $8^{\text {th }}$ among the 11 categorized surgical conditions, and $7.0 \%$ of the surgical cases which were presented between 1998 and 2008. Most of the intestinal conditions such as intussusception, volvulus and torsion were strangulating obstructive conditions and occurred more in small than large animals. Hernia ranked highest among the surgical conditions, followed by intussusception, volvulus and rectal prolapse in that order. The intestinal conditions were more prevalent in post mortem records and in small animals than in large animals. The findings in this study showed that intestinal surgical conditions are not uncommon in Veterinary hospital and clinics in the study area. It further showed that the management of intestinal surgical conditions is still a major challenge in some Veterinary hospital and clinics in Nigeria.

KEYWORDS: Hernia, Intussusception, Intestine, Large and Small Animals, Volvulus.

\section{INTRODUCTION}

Bowel obstructions, especially the strangulating types, are medical and surgical emergencies with grave consequences due to hypovolemia and septic shock secondary to devitalization of the intestinal wall (Holder, 1988; Hassinger, 1997). In small animals, bowel obstructions may be sequel to intussusception, volvulus, torsion, hernia, foreign bodies and neoplasias (Hassinger, 1997; Eyarefe et al., 2001). Intestinal volvulus, for instance, undergoes a par acute onset of signs, which may present a patient from a state of being normal to near death in less than 6 hours (Ellison, 1986). Rapid intervention in form of precise diagnosis, and radical bowel surgery are therefore necessary to guarantee patients' survival (Ellison, 1986). Besides, potential complications such as bowel ileus, adhesions and Short Bowel Syndrome (SBS) may sequel bowel resection and consequently task the clinical competence of the clinician, with resultant death of the patient (Eyarefe et al., 2008; Fernando et al., 2009). In Nigeria, although intestinal obstructive conditions in animal species are quite familiar, there is a dearth of information in literature on the incidence and management challenges in animal patients with intestinal obstructive disease conditions presented at the Veterinary hospitals and clinics. This study therefore investigated the incidence, and management of intestinal obstructive conditions presented at Veterinary hospitals and clinics in southwestern Nigeria.

\section{MATERIALS AND METHODS}

A retrospective study of hospital case records and post mortem data from the Veterinary Teaching Hospital, University of Ibadan; Oyo State Veterinary Hospital, Mokola, Ibadan; Vet Tec Clinic, Jericho, Ibadan; Ogun State Veterinary Hospital, Abeokuta; Ondo State Veterinary Hospital, Akure; and Pet Care Veterinary Hospital, Lagos obtained between 1998 and 2008 was done. Records of all surgical cases including intestinal obstructive conditions 
were grouped into 11 categories. Further grouping / categorization of the various types of intestinal obstructive conditions in small and large animals was also noted.

\section{DATAANALYSIS}

All data on various types of surgical conditions, including further grouping / categorization of intestinal obstructive conditions in small and large animals were presented using descriptive statistics.

\section{RESULTS}

The incidence of intestinal disease ranked $8^{\text {th }}$ among the 11 categorized surgical conditions, this represents $7.0 \%$ of surgery cases presented from 1999-2008 (Table I). Hernia ranked highest, followed by intussusception while rectal prolapsed and torsion ranked lowest among the intestinal conditions presented within the study period (Figure 1). The intestinal conditions were more prevalent in small animals than in large animals. Intussusception and foreign body impaction were observed in small animals only, while rectal prolapse, perforation and torsion were observed in large animals (figure 2). Non strangulating hernias were observed only as ante-mortem cases while intussusception was observed as both ante- and post-mortem cases, other intestinal condition were observed as postmortem cases (Figure 3 ).

Table I: Incidence of Surgical Conditions presented at Some Veterinary Hospitals and Clinics in South-West Nigeria (1999. 2008)

\begin{tabular}{l|l|l}
\hline Surgical Conditions & Frequency & Percentage \\
\hline Male Reproductive Surgeries & 141 & 21 \\
Tail Docking & 10 & 1 \\
Aural Haematoma & 58 & 9 \\
Transmissible Veneral Tumur & 42 & 6 \\
Orthopedic Surgeries & 169 & 26 \\
Eye Surgeries & 16 & 2 \\
Wound Repair & 79 & 12 \\
Female Reproductive Surgeries & 72 & 11 \\
Intestinal Surgeries & 50 & 7 \\
Abscess Lancing & 11 & 2 \\
Other types of Tumur & 19 & 3 \\
\hline
\end{tabular}

Figure 1: Surgical intestinal conditions presented at some Veterinary Hospitals and Clinics in South-West Nigeria (1999 2008)

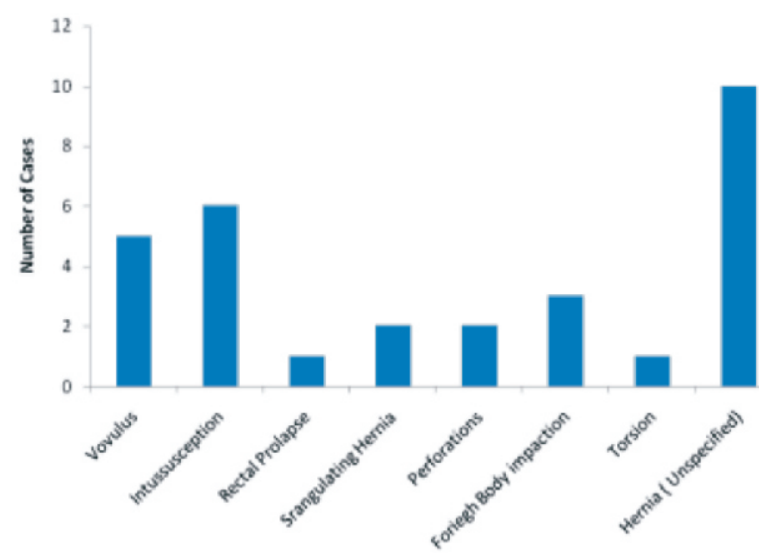

Figure 2: Comparison of small and large animals surgical intestinal conditions presented at some Veterinary Hospitals and Clinics in South-West Nigeria (1999 - 2008)



Figure 3: Comparison of intestinal surgical conditions obtained in animals between Postmortem and ante-mortem records in Veterinary Hospitals and Clinics in Southwestern Nigeria (19992008)



\section{DISCUSSION}

In this study, comparison of incidence of intestinal conditions with other surgical conditions was made. The results of this study show that intestinal obstructive conditions are presented in Veterinary Hospitals and Clinics in Nigeria. The choice of the Veterinary Hospitals and Clinics whose case records were studied was 
influenced by their size, standard of clinical practice and their status as referral centres. Intestinal conditions ranked $8^{\text {th }}$ of the 11 categorized surgical conditions, and $7.0 \%$ of surgical cases presented to the selected Veterinary Hospitals and Clinics. Most of these cases were strangulating obstructive conditions such as intussusception, volvulus and torsion which were recorded for large and small animals presented at these Veterinary centres. Strangulating obstructions are medical and surgical emergencies, causing rapid death often as result of hypovolemia and septic shock secondary to devitalization of the intestinal wall (Holder, 1988 ; Hassinger, 1997).

It has been previously reported that most animal patients (dogs and cats) presented intestinal volvulus without prior history of illness (Ellison, 1986, Holder, 1988 and Hassinger, 1997). Such intestinal volvulus undergo par acute onset of signs, and present a patient from a state of being normal to near death in less than 6 hours (Ellison, 1986). This may explain why greater numbers of these cases of intestinal diseases were obtained from post mortem records. In environments like ours, where most people pay less or delayed attention to the health of animals, such animals are likely to be found dead in the pen or kennel, and the option may be to dispose of the carcass without post mortem evaluation. Records of such cases are not usually available for this type of study, which may be responsible for the lower incidence, observed in this study.

Furthermore, some common clinical signs of mechanical or strangulation obstructions such as hematochezia, vomiting, and acute abdominal pains are also common with medical conditions such as helminthosis and parvovirus associated gastroenteritis in puppies, as well as canine distemper and leptospirosis in adult dogs (Larsen and Bellenger, 1974; Kirk and Bistner, 1975). There is a great chance of inexperience clinicians missing the diagnosis of these intestinal diseases, offer non-specific treatment, and patient may die thereafter. Postmortem evaluation of such animals may only be done if death occurred around the hospital environment or boarding kennel.

A higher incidence of hernia was observed in this study. Bowel translocations through rents in the mesentery or through hernias in umbilicus, diaphragm, inguinal and femoral triangle have been associated with extra-luminal small intestinal obstructions (Strombeck and Davis, 1979; Holder, 1988). That these hernias were clinically managed show that they were presented early enough with good prognosis. However, records of some animals with strangulating hernia were noted in postmortem case records (Figure 3 ).

Intussusception and volvulus ranked second and third respectively among the intestinal condition presented within the period studied (19982008). Intussusception and volvulus are two intestinal surgical emergencies with fatal consequences of fluid and electrolyte derangement especially when diagnosis and surgical treatment are delayed (Nemzek et al., 1993). When severe vascular compromise with devitalized large segments are involved, massive bowel resection is recommended which may have post operative potentials of precipitating short bowel syndrome (Gorman et al., 2006). Furthermore, there were more cases of the observed intestinal conditions in small animals than in large animals presented at the Veterinary Hospitals and Clinics. This may be due to the upsurge in acquisition and keeping of small animals (dogs) for security purpose and for companionship. Moreover, owners of food animals such as cattle, sheep and goat may prefer to curl an animal showing acute signs rather than present such for medical treatment. The animals may also die unnoticed since they are usually on free range, and when discovered, there may not be need to present the carcass for postmortem evaluation because of the degree of autolysis. In addition, the fact that these hospitals and clinics were located in major cities, and in south west geographical zone as against North east or North central (where large animals are more), may also have influenced the greater number of these conditions in small animals than in large animals.

In conclusion, diagnosis and management of intestinal surgical conditions are still major challenges in Veterinary hospital and clinics in Nigeria. The incidence of intestinal conditions observed in this study may be associated with defective diagnosis, nonspecific treatment and death of patients outside clinic or hospital 
environment without an option of postmortem evaluation for prevention and record purpose. Emphasis should therefore be given to training of Veterinary Surgeon in art of diagnosis and treatment of gastrointestinal conditions in animals. There is also the need to procure modern diagnostic equipments and skilled manpower to enhance quick diagnosis of these conditions.

\section{ACKNOWLEDGMENT}

The authors acknowledges with thanks the management and staff of the Veterinary Teaching Hospital, University of Ibadan, Oyo State Veterinary Hospital, Mokola, Ibadan, Vet. Tech. Veterinary Clinic, Jericho, Ibadan, Ogun State Veterinary Hospital, Abeokuta. Ondo State Veterinary Hospital, Akure, and PetCare Veterinary Hospital, Lagos.

\section{REFERENCES}

Ellison G.W. (1986): Surgical emergencies: contemporary issues in small animal practice. Churchill Livingstone; NE. London.

EYAREFE, O. D, ONI, S. O. and AKINRINMADE, J. F. (2001): Clinicopathological features of massive small intestinal resection in Nigeria's Local Breeds of Cats. Afr. J. Biomed Res 4: 33-37.
EYAREFE, O. D., EMIKPE, B. O. and AROWOLO, O. A. (2008): Small bowel responses to enteral honey and glutamine administration following massive small bowel resection in rabbit. Afr. J. Med and Medical Science 37: 309-314.

FERNANDO, N., WALLACE A., MARC RHOADS, K., and RUBEN, E. Q. (2009): Short Bowel Syndrome, Epidemiology, pathophysiology and adaptation. American Academy of Pediatrics 10 (7):330.

GORMAN, S.C., FREEMAN, L. M., MITCHELL, S.L., and CHAN, D.L. (2006): Extensive bowel resection in dogs and cats: 20 cases (1998-2004).JAVMA. 228.3:403-406.

HASSINGER, K. A. (1997): Intestinal entrapment and strangulation caused by rupture of the duodenocolic ligament in four dogs. Vet Surgery 26: 275.

HOLDER, W. D. (1988): Intestinal obstruction. Gastroenterol clin NAM. 17: 317.

KIRK, R.W., and S.I. BISTNER. (1975): Handbook of Veterinary Procedures and Emergency Treatment. 2nd ed. London: W.B.Saunders Company, p79-81.

LARSEN, L. H., and BELLENGER C. R (1974): Stomach and small intestine. Canine Surgery. 2nd Ed. J. Archibald and Santa Barbara .Eds. California, American Veterinary Publications, Inc. 583-585.

NEMZEK, J. A., WALSHAW R., and HAUPTMAN J. G. (1993): Mensenteric volvulus in the dog: an introspective study. $J$ Am. Animal Hospital Association 29: 357.

STROMBECK, D., and DAVIS, C. A. (1979): Small animal gastroenterology. Stonegate: 165-166. 